\title{
Fatores associados a acidentes de trânsito entre universitários
}

\author{
Associated factors with traffic accidents among college students \\ Factores asociados a accidentes de tráfico en estudiantes universitarios
}

Recebido: 04/01/2021 | Revisado: 05/01/2021 | Aceito: 10/01/2021 | Publicado: 13/01/2021

Roberta Barros de Miranda

ORCID: https://orcid.org/0000-0003-3257-6074

Universidade Estadual do Sudoeste da Bahia, Brasil

E-mail: roberta_betabarros@hotmail.com

Jarlan Santana de Souza

ORCID: https://orcid.org/0000-0002-2844-6333

Universidade Estadual do Sudoeste da Bahia, Brasil

E-mail: jarlansantanadsza@hotmail.com

Fernanda Oliveira Santos

ORCID: https://orcid.org/0000-0002-7200-4137

Universidade Estadual do Sudoeste da Bahia, Brasil

E-mail: nandasantos.fos@gmail.com

Artur Souza dos Santos

ORCID: https://orcid.org/0000-0001-5692-2328

Universidade Estadual do Sudoeste da Bahia, Brasil

E-mail: arthurneto14@ hotmail.com

Clarice Portela Fonsêca

ORCID: https://orcid.org/0000-0003-4815-2612 Universidade Estadual do Sudoeste da Bahia, Brasil

E-mail: clapfonseca19@gmail.com

Luciano Nery Ferreira

ORCID: https://orcid.org/0000-0002-9410-2467 Universidade Estadual do Sudoeste da Bahia, Brasil E-mail: lnery@uesb.edu.br

Polianna Alves Andrade Rios

ORCID: https://orcid.org/0000-0002-6318-2230 Universidade Estadual do Sudoeste da Bahia, Brasil E-mail: paarios@uesb.edu.br

Jefferson Paixão Cardoso

ORCID: https://orcid.org/0000-0003-0128-5792 Universidade Estadual do Sudoeste da Bahia, Brasil E-mail: jpcardoso@uesb.edu.br

\begin{abstract}
Resumo
Este estudo objetivou identificar fatores associados aos Acidentes de Trânsito (AT) entre estudantes universitários e verificar associação entre comportamentos de risco e AT nessa população. Trata-se de um estudo de corte transversal, exploratório, com estudantes de graduação de uma universidade pública da Bahia, no ano de 2019. Participaram desta pesquisa 276 estudantes, maioria mulheres $(74,6 \%)$. Dos universitários, 55 se envolveram em AT, a maior prevalência foi para o sexo feminino $(63,6 \%)$, solteiros $(17,8 \%)$, aqueles cujo pai não completou o $1^{\circ}$ grau $(47,2 \%)$, que não trabalhavam (49\%), e condutores de motocicleta (49\%), exibindo associação com o desfecho, apresentando valor de $\mathrm{p}$ $=0,036, \mathrm{p}=\langle 0,001, \mathrm{p}=0,014, \mathrm{p}=0,001, \mathrm{p}=<0,001$, respectivamente. Trabalhar além de estudar, ser usuário da categoria condutor de motocicleta, e dirigir motocicleta, apresentaram maior chance de ter se envolvido em AT, respectivamente em 1,54, 1,28, 1,95 vezes. Ao passo que estudantes que tinham pais/familiares que sempre respeitavam as regras de trânsito apresentaram $45 \%$ menor chance de ter se envolvido em AT.
\end{abstract}

Palavras-chave: Acidente de trânsito; Estudantes; Fatores de risco.

\begin{abstract}
This study aims to identify factors associated with Traffic Accidents (TA) among university students and verify the association between risky behavior and TA in this population. This is a cross-sectional, exploratory study with undergraduate students from a public university in Bahia, in 2019. 276 students participated, mostly women (74.6\%). Of the university students, 55 were involved in TA, the highest prevalence was for females $(63.6 \%)$, single (17.8\%), those whose father did not complete primary school (47.2\%), who did not work (49\%), and motorcycle drivers (49\%), showing an association with the outcome, $\mathrm{p}=0.036, \mathrm{p}=\langle 0.001, \mathrm{p}=0.014, \mathrm{p}=0.001, \mathrm{p}=<0.001$, respectively. Working in addition to studying, being a user of the motorcycle driver category, and driving a motorcycle, a greater chance of having a relationship with AT, 1.54, 1.28, 1.95 times, respectively. Whereas students who studied parents / family members who always respected the traffic rules dissipated $45 \%$ less chance of having spread in TA.
\end{abstract}

Keywords: Traffic accident; Students; Risk factors. 


\section{Resumen}

Este estudio tiene como objetivo identificar los factores asociados a los Accidentes de Tránsito (AT) en estudiantes universitarios y verificar la asociación entre conductas de riesgo y AT en esta población. Se trata de un estudio exploratorio transversal con estudiantes de pregrado de una universidad pública de Bahía, en 2019. Participaron 276 estudiantes, en su mayoría mujeres (74,6\%). De los estudiantes universitarios, 55 estaban involucrados en AT, la mayor prevalencia fue para mujeres $(63,6 \%)$, solteras $(17,8 \%)$, aquellas cuyo padre no completó la escuela primaria $(47,2 \%)$, que no trabajaban $(49 \%)$ y motociclistas $(49 \%)$, mostrando asociación con el resultado, con un valor de $\mathrm{p}=$ $0.036, \mathrm{p}=<0.001, \mathrm{p}=0.014, \mathrm{p}=0.001, \mathrm{p}=<0.001$, respectivamente. Trabajar además de estudiar, ser usuario de la categoría de conductor de motocicleta y conducir una motocicleta, tuvo una mayor probabilidad de haber estado involucrado en AT, 1,54, 1,28, 1,95 veces, respectivamente. Mientras que los estudiantes que tenían padres / miembros de la familia que siempre respetaban las reglas de tráfico tenían un $45 \%$ menos de probabilidades de haber participado en TA.

Palabras clave: Accidente de tráfico; Estudiantes; Factores de riesgo.

\section{Introdução}

O trânsito brasileiro é motivo de estudos comportamentais desde o final do século passado com o surgimento do novo Código de Trânsito Brasileiro (CTB), estabelecido em 1997 (Bastos et al., 1999). De acordo com a Organização Mundial da Saúde (OMS) anualmente ocorrem mais de 1 milhão de mortes por Acidente de Trânsito (AT), ocupando assim o ranking das 10 principais causas de morte no mundo, sendo que estudos populacionais revelam que dessas mortes, a maioria afeta jovens de idade igual ou inferior a 29 anos (OMS, 2018; OPAS, 2018).

No Brasil, as mortes por AT ocupam o $2^{\circ}$ lugar entre as principais causas de óbito entre os jovens (Filho et al., 2017). Diversos fatores podem estar associados a essa ocorrência, bem como a de lesões no trânsito, a exemplo dos fatores estruturais das vias e automóveis e aspectos comportamentais, como o uso do celular, não uso de equipamentos de segurança e o uso de bebida alcóolica, práticas comuns entre os jovens (Andrade et al., 2003).

Ainda que os AT no Brasil acometam indivíduos de todas as idades, entre 2016 e 2018 as internações de jovens foram mais elevadas do que de outras faixas etárias. Um dos maiores desafios da saúde pública é a atenuação desses acidentes, tornando-se fundamental a realização de estudos nessa área, a fim de compreender este tema, para elaboração de métodos de prevenção e promoção da segurança no trânsito (Carneiro, 2019).

Diante do exposto, este estudo teve como objetivo identificar os fatores associados a acidentes de trânsito entre estudantes universitários, bem como verificar associação entre comportamentos de risco e acidentes de trânsito nessa população.

\section{Metodologia}

Estudo epidemiológico transversal, exploratório, quantitativo, do tipo inquérito on-line (Eysenbach \& Wyatt, 2002) efetivado com discentes matriculados em cursos de graduação da Universidade Estadual do Sudoeste da Bahia, campus de Jequié, durante o ano de 2019. É importante destacar, que também como fruto desse desenho de pesquisa, desenvolveu-se e desenvolve-se outras investigações com diferentes objetivos de estudo, a exemplo do trabalho de Souza et al., (2020), o qual analisou os fatores associados à comportamento de risco relacionados ao consumo de bebida alcoólica em estudantes universitários.

A coleta de dados foi realizada a partir da lista atualizada dos nomes e e-mails dos universitários adquirida na secretaria setorial de cursos da universidade. Utilizou-se um questionário eletrônico elaborado na plataforma Google Forms, contendo 60 itens extraídos e adaptados de instrumentos de inquéritos nacionais que pesquisaram acidentes de trânsito, como a Pesquisa Nacional por Amostra de Domicílio (PNAD) de 2008 e a Pesquisa Nacional de Saúde (PNS) de 2013; e de outra investigação realizada em 2013 pelo Núcleo de Estudos em Saúde e Trânsito (NESTran).

As variáveis utilizadas neste estudo foram: 
- Sociodemográficas: sexo (masculino; feminino), idade, cor de pele (branca; amarela; indígena; parda; preta), estado civil (casado/união estável; divorciado/separado; viúvo; solteiro), grau de escolaridade de pais (universitário/ensino superior completo; $2^{\circ}$ grau completo; $1^{\circ}$ grau completo; $1^{\circ}$ grau incompleto; não estudou), emprego durante os estudos (sim; não), carga horária semanal de trabalho fora da universidade, tempo de serviço e tipo de vínculo da ocupação (público municipal; público estadual; público federal; privado; empregado sem vínculo formal; autônomo);

- $\quad$ Acadêmicas: curso de graduação, semestre em curso (até o $5^{\circ}$ semestre; do $6^{\circ}$ semestre em diante), e ingresso na universidade utilizando ações afirmativas (sim; não);

- $\quad$ Referentes a mobilidade urbana e condução de veículos motorizados: tipo de locomoção nos últimos 12 meses (pedestre; ciclista; passageiro de carro; transporte coletivo ou motocicleta), conduzir automóvel (sim; não), e conduzir motocicleta (sim; não);

- Referentes ao comportamento dos pais/familiares no trânsito: pais/familiares costumam respeitar as regras de trânsito (não; as vezes; frequentemente).

- $\quad$ Referentes ao uso do celular durante condução de automóveis: atende e/ou faz ligações de celular enquanto dirige carro ou moto; ler ou manda mensagens de texto e voz pelo celular enquanto dirige carro ou moto (não, nunca; sim, às vezes; sim, frequentemente; não, dirijo carro ou moto);

- Referente ao envolvimento nos últimos 12 meses a realização da pesquisa em algum AT (sim; não).

A análise descritiva foi utilizada para caracterizar a população do estudo e estimar as frequências das variáveis com proporções e médias. Para análise de fatores associados foram realizadas duas etapas. A primeira etapa consistiu na análise de associações entre variáveis, verificada por meio do teste qui quadrado para as variáveis categóricas. Utilizou-se também o teste $\mathrm{t}$ de student para avaliar a diferença de médias entre grupos, para variáveis numéricas. Em ambos, adotou-se como critério de significância estatística o valor de $\mathrm{p} \leq 0,05$.

Para a segunda etapa, procedeu-se a utilização de modelo de Regressão Logística com estimação da odds ratio (OR) com Intervalos de Confiança de $95 \%$. Nesta etapa, foram levados para o modelo saturado as variáveis que mantiveram associação com o desfecho a um valor de p máximo de 0,2 na primeira etapa, além de algumas variáveis que, mesmo não atendendo ao critério, tinham importância do ponto de vista teórico para uma provável explicação do desfecho.

As variáveis foram retiradas do modelo uma a uma a partir da lógica backward, observando-se o valor de $\mathrm{p}$ ajustado para as demais variáveis e a bondade de ajuste do modelo. O modelo final foi considerado aquele cujo conjunto de variáveis melhor se ajustou, apresentando valores pontuais e intervalares com razoável potencial explicativo para o conjunto de variáveis.

Este estudo foi aprovado pelo Comitê de Ética em Pesquisa (CEP) da Universidade Estadual do Sudoeste da Bahia, com parecer $\mathrm{n}^{\circ} 2.240 .219$.

\section{Resultados}

Compuseram a amostra desse estudo 276 universitários, maioria do sexo feminino $(74,6 \%)$, cor de pele auto referida parda $(52,5 \%)$ e estado civil solteiro $(89,1 \%)$. Também, a maior frequência dos participantes foi entre os que cursavam graduações das ciências da saúde $(72,5 \%)$, que estudavam do $6^{\circ}$ semestre em diante $(51,1 \%)$ e adentraram a universidade por meio da ampla concorrência (Tabela 1). Quanto à idade, a média entre os investigados foi de 23 anos, com desvio padrão de 4,6 . 
Tabela 1. Características sociodemográficas e acadêmicas dos graduandos. Jequié, Bahia, 2019.

\begin{tabular}{|c|c|c|}
\hline Variáveis & $\bar{n}$ & $\%$ \\
\hline \multicolumn{3}{|l|}{ Sexo } \\
\hline Masculino & 70 & 25,4 \\
\hline Feminino & 206 & 74,6 \\
\hline \multicolumn{3}{|l|}{ Cor da pele } \\
\hline Branca & 50 & 18,1 \\
\hline Preta & 80 & 29,0 \\
\hline Parda & 145 & 52,5 \\
\hline Amarela & - & - \\
\hline Indígena & 1 & 0,4 \\
\hline \multicolumn{3}{|l|}{ Estado civil } \\
\hline Casado/união estável & 25 & 9,1 \\
\hline Divorciado/separado & 5 & 1,8 \\
\hline Solteiro & 246 & 89,1 \\
\hline \multicolumn{3}{|l|}{ Área de curso } \\
\hline Artes (Dança, Teatro) & 11 & 3,9 \\
\hline Ciências Exatas (Matemática, Química, Sistemas de Informação) & 28 & 10,1 \\
\hline Ciências Humanas (Letras, Pedagogia) & 37 & 13,5 \\
\hline $\begin{array}{l}\text { Ciências da Saúde (Biologia, Educação Física, Enfermagem, Farmácia, } \\
\text { Fisioterapia, Medicina, Odontologia) }\end{array}$ & 200 & 72,5 \\
\hline \multicolumn{3}{|l|}{ Semestre } \\
\hline Até o $5^{\circ}$ semestre & 135 & 48,9 \\
\hline $6^{\circ}$ semestre em diante & 141 & 51,1 \\
\hline \multicolumn{3}{|l|}{ Cotas } \\
\hline Sim & 121 & 43,8 \\
\hline Não & 155 & 56,2 \\
\hline
\end{tabular}

Fonte: Dados da pesquisa (2019).

Os resultados demonstram que 38,7\% dos estudantes trabalhavam e a sua carga horária média de trabalho era de 33 horas semanais, com média do tempo de ocupação de 45,5 meses. O tipo de vínculo com maior ocorrência foi o Público Estadual (37,8\%). Ainda, em relação ao uso do celular, 13,7\% atendiam e/ou faziam ligações e 12,6\% liam ou mandavam mensagens de texto e voz enquanto dirigiam carro ou moto.

Dos investigados, 55 sofreram AT nos 12 meses anteriores à pesquisa (Tabela 2). A maior ocorrência foi entre os discentes do sexo feminino (63,6\%), estado civil solteiro $(17,8 \%)$, cuja a escolaridade do pai era incompleta no $1^{\circ}$ grau (47,2\%), não trabalhavam além de estudar (49\%), quanto o tipo de usuário do trânsito, eram condutores de moto (49\%), que confirmaram dirigir carro $(50,9 \%)$ e confirmaram dirigir moto $(63,6 \%)$. Todas essas variáveis exibiram associação com o desfecho estudado, respectivamente com valor de $\mathrm{p}=0,036, \mathrm{p}=<0,001, \mathrm{p}=0,014, \mathrm{p}=0,001, \mathrm{p}=<0,001, \mathrm{p}=0,005$ e $\mathrm{p}=$ $<0,001$.

Em relação ao uso do aparelho celular no trânsito, 12,7\% dos que sofreram AT afirmaram às vezes utilizá-lo para atender e/ou fazer ligações $(\mathrm{p}=0,013)$ e 16,3\% para ler ou enviar mensagens de texto e voz $(\mathrm{p}=0,041)$. Também, houve maior ocorrência de AT entre aqueles cujos pais frequentemente respeitavam as regras de trânsito $(58,1 \%)$, contudo esse resultado não apresentou significância estatística.

Tabela 2. Fatores associados a ocorrência de acidentes de trânsito entre universitários nos últimos 12 meses. Jequié, Bahia, 2019.

n $\quad$ n $\quad$ Valor de $\mathbf{p}$


Sexo

Feminino

Masculino

Estado civil

Casado/União estável

Divorciado/Separado

Solteiro

Escolaridade do pai

Universitário/Superior completo

$2^{\circ}$ grau completo

$1^{\circ}$ grau completo

$1^{\circ}$ grau incompleto

Não estudou

Trabalha além de estudar

Não

Sim, como Bolsista na UESB

Sim, em outra instituição/local

Tipo de usuário

Ciclista

Condutor de motocicleta

Motorista de carro

Passageiro de carro

Passageiro de Motocicleta

Passageiro de transporte coletivo (Ônibus)

Pedestre

Condutor de carro

Não dirige carro

Dirige carro

Condutor de moto

Não dirige moto

Dirige moto

Atender e/ou fazer ligações de celular

Não, nunca

Sim, às vezes

Sim, frequentemente

Não dirijo carro ou moto

Ler ou mandar mensagens de texto e voz

Não, nunca

Sim, às vezes

Sim, frequentemente

Não dirijo carro ou moto

Pais/familiares costumam respeitar as regras de trânsito

Não

Às Vezes

Frequentemente
0,036

$<0,001$

0,014

05,4

38,1

09,0

47,2

0,001

49,0

21,8

29,0

$<0,001$

49,0

14,5

12,7

3,6

20,0

0,005

$<0,001$

0,013

63,6

12,7

23,6

0,041

$129 \quad 33 \quad 60,0$

$35 \quad 09 \quad 16,3$

$\begin{array}{rrr}01 & - & - \\ 111 & 13 & 23,6\end{array}$

$04 \quad 02 \quad 03,6$

$85 \quad 21 \quad 38,1$

$187 \quad 32 \quad 58,1$

Fonte: Dados da pesquisa (2019).

A regressão logística revelou que os estudantes que também trabalhavam apresentaram 1,54 vezes mais chance de terem de envolvido em AT com IC95\% 1,02 - 2,33 (Tabela 3), quando comparado com os estudantes que não trabalhavam. Dos tipos de usuários, os condutores de motocicleta, bem como os que afirmaram dirigir moto, apresentaram 1,28 (IC95\% 1,09 - 1,50) e 1,95 (IC95\% 0,92 - 4,14) vezes mais chances de terem se envolvido em AT, quando comparado com os outros tipos de usuário do trânsito e com os que não dirigiam moto. Apesar dos estudantes cujos pais/familiares frequentemente costumavam respeitar as regras de trânsito apresentarem maior ocorrência de AT, a regressão logística evidenciou que esta variável se apresentou como um fator de proteção ao AT, exibindo $45 \%$ menor chance do participante ter se envolvido em AT, quando comparados com os participantes que os pais/familiares não respeitavam ou às vezes respeitavam as regras de trânsito. 
Tabela 3. Razão de chances de ter se envolvido em acidente de trânsito. Jequié, Bahia, 2019.

Trabalha além de estudar

Tipo de usuário (condutor de motocicleta)

Dirige motocicleta

Pais/familiares costumam respeitar as regras de trânsito
Odds Ratio (OR)

1,54

1,28

1,95

0,55
Intervalo de Confiança - 95\%

$1,02-2,33$

$1,09-1,50$

$0,92-4,14$

$0,30-1,02$

Fonte: Dados da pesquisa (2019).

\section{Discussão}

A Agência Brasileira de Normas Técnicas (ABNT), por meio da NBR 10.697 de 1989, define o AT como "qualquer evento não premeditado de que resulte dano em veículo ou na sua carga e ou lesões em pessoas e ou animais, em que pelo menos uma das partes está em movimento nas vias terrestres ou áreas abertas ao público". A referida norma, também classifica os acidentes em simples, quando não possuem vítimas e não gera nenhum tipo de prejuízo, e graves, quando existindo ou não vítimas, há prejuízos à via, trânsito ou meio ambiente.

Seguindo esse entendimento, as lesões provenientes dos AT refletem em déficits econômicos consideráveis, tanto para os que se envolvem diretamente, como para familiares e governo. Para a maioria dos países, estima-se que os AT custem 3\% do Produto Interno Bruto (PIB), tais gastos decorrem por exemplo das despesas com tratamentos, bem como da redução e perda de produtividade (OPAS, 2019). Desse modo, é importante compreender os aspectos epidemiológicos desses eventos, afim de que o Estado não atue apenas na recuperação, mas na promoção e proteção aos agravos, o que será menos oneroso (Massaú \& Rosa, 2016).

Nesse sentido, a informação encontrada neste estudo, que as mulheres foram as que mais se envolveram em AT, diverge do encontrado predominantemente na literatura, onde os homens são os que mais se envolvem nesses eventos (Filho et al. 2017; Lima \& Junior, 2017). Evidenciando tal informação, o Seguro de Danos Pessoais Causados por Veículos Automotores de Via Terrestre (DPVAT), revela que no ano de 2017, 75\% e 82\% das indenizações pagas por AT não fatais e fatais respectivamente, foram para os indivíduos do sexo masculino.

Contudo, salienta-se a crescente participação das mulheres como condutoras no trânsito, principalmente no comando das motocicletas, o que pode estabelecer associação com os achados dessa pesquisa. De acordo com a Associação Brasileira dos Fabricantes de Motocicletas, Ciclomotores, Motonetas, Bicicletas e Similares (ABRACICLO), ocorreu entre 2011 e 2019 um crescimento de $89,2 \%$ no número de mulheres habilitadas na categoria A. Refletindo tais mudanças, Rios e colaboradores (2019) demonstram em seu estudo a ausência de associação entre ocorrência de AT e sexo, não havendo distinção entre homens e mulheres.

A maior prevalência dos AT entre os indivíduos solteiros destaca-se também em outros estudos, como apontam duas pesquisas distintas que investigaram o perfil dos óbitos por AT nas cidades de Barbacena entre 2004 e 2014 e Belo Horizonte entre 2010 e 2011, onde respectivamente, 56,3\% e 68,0\% das mortes ocorreram com vítimas de estado civil solteiro (Campos et al., 2016; Paixão et al., 2015). Campos e colaboradores (2016), inferiram que esse fenômeno esteja associado ao fato desses indivíduos tenderem a se tornar mais propensos a situações de risco, por não possuírem família e projeto de vida.

Outro fator a ser discutido, é a influência direta dos pais sobre o comportamento no trânsito dos filhos, os quais comumente reproduzem suas atitudes (Jorge \& Martins, 2013). Em razão disso, o achado de que filhos de pais com $1^{\circ}$ grau incompleto sofreram mais acidentes pode relacionar-se ao fato de que indivíduos com menor escolaridade possuem menor percepção de risco no trânsito, quando comparados com os que estudaram mais, a exemplo do entendimento das principais causas de AT, conhecimento dos limites de velocidade e aplicação das multas (ABEETRANS, 2019). 
Chamamos atenção também, o resultado que estudantes que trabalham apresentaram maiores chances de terem se envolvido em AT, o que aqui podemos associar a maior exposição desses indivíduos ao ambiente do trânsito, durante seu tráfego entre casa e trabalho, bem como, considerar como um possível fator associado a maior carga de estresse e fadiga física desses discentes, pois agregam às suas jornadas de estudos, extensas jornadas de trabalho (Lacerda, et al., 2014).

Como destaca o Mapa da motorização individual no Brasil (2019), entre os anos de 2008 e 2018 a frota de motocicletas foi acrescida em 13,7 milhões no país, com maior expressividade no Nordeste e em cidades pequenas, o que caracteriza bem o município de Jequié, localizado no interior de um dos estados dessa região. Isso, mantém relação com a praticidade na mobilidade e facilidade de acesso desse meio de transporte, que possui baixo custo de aquisição e manutenção (Faria, 2015). Assim, compreende-se a maior ocorrência e chance de ter se envolvido em AT entre o tipo de usuário motociclista.

Corroborando com essas informações, investigação realizada na cidade de São Paulo, entre os anos de 2011 e 2013, com a finalidade de descrever o perfil das vítimas de AT com motocicletas, demonstrou que as principais as vítimas foram os jovens, com a predominância da faixa etária entre os 20 a 29 anos. Dessa maneira, destaca-se a necessidade de atividades educativas por meio de políticas públicas destinadas a esse grupo, a fim de que respeitem as regras de trânsito e melhor entendam os riscos associados a condução de motocicletas (Rodrigues et al., 2014).

Ademais, é importante salientar a maior vulnerabilidade a que os condutores de motos estão expostos, pois esse é um veículo menor, com maior chance de não ser visto por outros condutores, que possui apenas duas rodas, com maior sujeição à perda da estabilidade lateral e que não possui proteção equiparada aos carros, absorvendo em situações de colisão toda a energia gerada no impacto, o que provoca lesões mais graves e maiores proporções de óbito (Zabeu et al., 2013; Ferraz et al., 2012).

Ainda, foi possível observar comportamentos que infringem o CTB, mesmo que não realizados com frequência, a exemplo da utilização do aparelho celular durante a condução de automóveis, tanto para realização de chamadas, quanto envio de mensagens. Estas atitudes são completamente vedadas pela lei no 9.503/97, que as considera infrações gravíssimas, já que o uso de tal equipamento promove distração, aumentando o risco de AT (Santos \& Rey, 2018). Ratificando essas informações, estudo com 203 universitários de Sorocaba, aponta que quase 40\% dos entrevistados nunca param suas chamadas no trânsito e que dos $28 \%$ que já se acidentaram, em $10 \%$ dos casos o celular estava sendo utilizado no momento do AT, por eles mesmos ou por outros condutores (Ilias et al., 2012).

Carter et al., 2014, apresentam a importância da influência normativa dos pais sobre as atitudes no trânsito dos filhos. Os progenitores modelam por meio do controle parental os padrões de condução desses, que por sua vez baseiam-se no comportamento e interpretação das normas e valores sociais dos seus pais. Destaca também, que jovens com bons modelos, que estabelecem limites específicos e claros sobre segurança no trânsito, mostram-se mais comprometidos com a direção segura e menos agressiva. Desse modo, justifica-se o positivo resultado evidenciado nesta pesquisa, com a redução de $45 \%$ das chances em terem se envolvido em AT, entre os universitários cujo os pais e familiares respeitavam frequentemente as regras de trânsito.

\section{Conclusão}

As análises deste estudo indicam que os universitários do sexo feminino, estado civil solteiro, que o pai não completou $01^{\circ}$ grau, que não trabalhavam e conduziam motocicleta, tiveram maior ocorrência de AT, com todas essas variáveis apresentando associação estatística com os AT. Trabalhar além de estudar, ser usuário da categoria condutor de motocicleta e dirigir motocicleta, aumentaram a chance de ter se envolvido em AT. Além disso, ter pais/familiares que frequentemente respeitam as regras de trânsito representou um fator de proteção, reduzindo a chance de ter se envolvido em 
AT.

Assim, sugere-se que novas investigações sejam realizadas com o intuito de identificar a existência de outros fatores associados à ocorrência de AT entre estudantes universitários.

\section{Agradecimentos}

Ao Conselho Nacional de Desenvolvimento Científico e Tecnológico (CNPq) pelo apoio financeiro, por meio da concessão de Bolsa de Iniciação Científica.

\section{Referências}

ABEETRANS. (2019). Pesquisa de Opinião Pública Geral (Motoristas e Pedestres). Associação Brasileira das Empresas de Engenharia de Trânsito (ABEETR.ANS) http://www.abeetrans.com.br/abeetrans/wp-content/uploads/2019/09/Pesquisa-Abeetrans-Parana.pdf.

ABRACICLO. (2020). Número de mulheres habilitadas na categoria A, de motociclistas, cresce 89,2\% em oito anos. Associação Brasileira de Ciclomotores, Motonetas, Bicicletas e Similares (ABRACICLO) https:/www.abraciclo.com.br/site/press-releases-2020/2020/numero-de-mulheres-habilitadas-na-categoriaa-de-motociclistas-cresce-892-em-oito-anos/ <<.

ABNT. (1989). NBR 10697/TB331 - Pesquisa de Acidentes de Trânsito. Associação Brasileira de Normas Técnicas (ABNT).

Bastos, Y. G. L., Andrade, S. M. D., \& Junior, L. C. (1999). Acidentes de trânsito e o novo Código de Trânsito Brasileiro em cidade da Região Sul do Brasil. Informe Epidemiológico do SUS, 8(2), 37-45.

Brasil. (2008). Código de Trânsito Brasileiro. Código de trânsito brasileiro: instituído pela Lei no 9.503. de 23-9-97-3ª edição-Brasília: DENATRAN.

Campos, M. P., Ferreira, A. M., Bolina, C. C., Neto, C. M., Costa, G. D., Mendes, R. D. S., \& Vidal, C. E. L. (2016). Relação entre alcoolemia e mortes por acidente de trânsito no município de Barbacena-MG de 2009 a 2014. Rev Med Minas Gerais, 26 (Supl 5), S128-S133.

Carneiro, F. de M. (2019). Estatísticas de acidentes de trânsito ocorridos entre 2016 e 2018, com foco no número de mortes e faixa etária das vítimas.

Carter, P. M., Bingham, C. R., Zakrajsek, J. S., Shope, J. T., \& Sayer, T. B. (2014). Social norms and risk perception: Predictors of distracted driving behavior among novice adolescent drivers. Journal of Adolescent Health, 54(5), S32-S41.

De Andrade, S. M., Soares, D. A., Braga, G. P., Moreira, J. H., \& Botelho, F. M. (2003). Comportamentos de risco para acidentes de trânsito: um inquérito entre estudantes de medicina na região sul do Brasil. Rev. Assoc. Med. Bras. (1992), 49(4), 439-44.

Eysenbach, G. \& Wyatt, J. (2002). Using the Internet for Surveys and Health Research. Journal of Medical Internet Research., 4(2):e13.

Faria, Y. de O. (2015). Prevalência de comportamentos de risco entre jovens universitários.

Ferraz, A. C. P. (2012). Segurança viária. São Paulo: São Carlos. Suprema Gráfica e Editora.

Ilias, D., Baras, F. C., Martinez, J. E., Santucci, V. C. R., \& Nascimento, S. R. D. (2012). Uso do telefone celular ao dirigir entre universitários. Revista da Faculdade de Ciências Médicas de Sorocaba, 14(3), 123-125.

Jorge, M. H. P. M., \& Martins, C. B. (2013). A criança, o adolescente e o trânsito: algumas reflexões importantes. Revista da Associação Médica Brasileira, 59(3), 199-208.

Lacerda, K. M., Fernandes, R. D. C. P., Nobre, L. C. D. C., \& Pena, P. G. L. (2014). A (in) visibilidade do acidente de trabalho fatal entre as causas externas: estudo qualitativo. Revista Brasileira de Saúde Ocupacional, 39(130), 127-135.

Lima, L. C., \& Júnior, V. D. S. C. (2017). Fatores associados à ocorrência de acidentes de trânsito no Brasil em 2013. Revista Latinoamericana de Población, 11(21), 167-179.

Massaú, G. C., \& da Rosa, R. G. (2016). Acidentes de trânsito e direito à saúde: prevenção de vidas e economia pública. Revista de Direito Sanitário, 17(2), 30-47.

Mesquita Filho, M., de Carvalho, C. R., \& de Paula Garcia, E. (2017). Fatores associados à ocorrência de acidentes de trânsito entre universitários. Ciência \& Saúde, 10(2), 62-70.

Observatório Das Metrópoles. (2019). Mapa motorização da individual https://www.observatoriodasmetropoles.net.br/wpcontent/uploads/2019/09/mapa_moto2019v2.pdf.

OMS. (2018). Global status report on road safety 2018. Organização Mundial da Saúde (OMS).

OPAS. (2019). Folha informativa - Acidentes de trânsito. Organização Pan-Americana da Saúde (OPAS) https://www.paho.org/bra/index.php?option=com_content\&view=article\&id=5147:acidentes-de-transito-folha-informativa\&Itemid=779

OPAS. (2018). Salvar VIDAS - Pacote de medidas técnicas para a segurança no trânsito. Organização Pan-Americana da Saúde (OPAS). 
Research, Society and Development, v. 10, n. 1, e26210111668, 2021

(CC BY 4.0) | ISSN 2525-3409 | DOI: http://dx.doi.org/10.33448/rsd-v10i1.11668

Paixão, L. M. M. M., Gontijo, E. D., Mingoti, S. A., Costa, D. A. D. S., Friche, A. A. D. L., \& Caiaffa, W. T. (2015). Óbitos no trânsito urbano: qualificação da informação e caracterização de grupos vulneráveis. Cadernos de Saúde Pública, 31, 92-106.

Rios, P. A. A., Mota, E. L. A., Ferreira, L. N., Cardoso, J. P., Santos, G. J., \& Rodrigues, T. B. (2019). Acidentes de trânsito com condutores de veículos: incidência e diferenciais entre motociclistas e motoristas em estudo de base populacional. Revista Brasileira de Epidemiologia, 22 , e190054.

Rodrigues, C. L., Armond, J. D. E., Gorios, C., \& Souza, P. C. (2014). Acidentes que envolvem motociclistas e ciclistas no município de São Paulo: caracterização e tendências. Revista Brasileira de Ortopedia, 49(6), 602-606.

Santos, J. N., \& Rey, L. A. S. (2018). Uso do aparelho celular no trânsito. $e-R A C, 8(1)$.

Seguradora Líder. (2018). Boletim estatístico seguradora líder- DPVAT: edição especial mulheres no trânsito. https://www.seguradoralider.com.br/Documents/boletim-estatistico/boletim_estatistico_mulheres-no-transito.pdf.

Souza, J. S. de, Fonsêca, C. P., de Miranda, R. B., Santos, F. O., dos Santos, A. S., Ferreira, L. N., ... \& Cardoso, J. P. (2020). Consumo de bebida alcoólica e comportamentos de risco no trânsito em estudantes universitários. Research, Society and Development, 9(11).

Zabeu, J. L. A., Zovico, J. R. R., Júnior, W. N. P., \& Neto, P. F. T. (2013). Perfil de vítima de acidente motociclístico na emergência de um hospital universitário. Revista Brasileira de Ortopedia, 48(3), 242-245. 